\title{
Avaliação da Perda Endógena de Aminoácidos, em Função de Diferentes Níveis de Fibra para Suínos 1
}

\author{
Paulo Cesar Pozza², Paulo Cezar Gomes ${ }^{3}$, Horacio Santiago Rostago ${ }^{3}$, Juarez Lopes \\ Donzele $^{3}$, Magali Soares dos Santos ${ }^{2}$, Rony Antônio Ferreira ${ }^{4}$
}

\begin{abstract}
RESUMO - O experimento foi conduzido com o objetivo de avaliar as perdas ileais endógenas de aminoácidos, em função de diferentes níveis de inclusão de fibra em uma dieta isenta de proteína. Foram utilizados oito suínos mestiços, machos castrados, com peso médio inicial de 50,17 $\pm 4,10 \mathrm{~kg}$, submetidos previamente à cirurgia para implantação de cânula "T" simples, distribuídos em um delineamento experimental de blocos ao acaso, com quatro tratamentos, quatro repetições e um animal por unidade experimental. Os tratamentos consistiram de uma dieta isenta de proteína, com quatro níveis de inclusão de casca de arroz, que proporcionaram níveis de 1,00, 2,00, 3,00 e 4,00\% de fibra bruta e, ou, 1,82, 3,64, 5,46 e 7,28\% de fibra em detergente neutro. Foram determinados os teores de matéria seca, proteína bruta, cromo e aminoácidos das digestas e das rações experimentais. Observou-se grande variação entre as perdas endógenas de aminoácidos, dentro do mesmo tratamento. Conclui-se que, entre os aminoácidos estudados, apenas a glicina não apresentou resposta significativa aos níveis de inclusão de fibra à dieta isenta de proteína, ocorrendo aumento da perda endógena dos demais aminoácidos, à medida que os níveis de fibra na dieta se elevaram.
\end{abstract}

Palavras-chave: aminoácidos, fibra, perda endógena, suínos

\section{Evaluation of Endogenous Amino Acids Losses in Function of Different Fiber Levels for Swine}

\begin{abstract}
The experiment was carried out with the objective of evaluating the ileal endogenous losses of amino acids in function of different fiber levels inclusion in a free protein diet. Were used eight crossbreed swine, castrated males, averaging $50.17 \pm 4.10 \mathrm{~kg}$ initial weight, submitted previously to the simple T canula surgery implantation, allotted to a randomized blocks design, with four treatments, four replicates and one animal per experimental unit. The treatments consisted in a free protein diet with four levels of rice husks inclusion, that provided levels of 1.00, 2.00,3.00, and 4.00\% of crude fiber and/or 1.82, 3.64, 5.46, and 7.28\% neutral detergent fiber. Contents of dry matter, crude protein, chromium and amino acids of the ilel samples and experimental rations were determined. It was observed a great variation among the amino acids endogenous losses, within treatments. It was concluded that, among the studied amino acids, just the glycine did not show significant effect to the fiber levels inclusion in the free protein diet, and there was an increase in the endogenous losses of the other amino acids, as the fiber levels in the diet increased.
\end{abstract}

Key Words: amino acids, endogenous losses, fiber, swine

\section{Introdução}

Os valores de digestibilidade ileal de aminoácidos dos ingredientes que compõem uma dieta podem ser expressos em digestíveis aparentes e, ou, verdadeiros, devendo ser ressaltado que esta última considera as perdas endógenas de aminoácidos. Desta forma, os valores de digestibilidade ileal verdadeira são maiores que os valores de digestibilidade ileal aparente. Portanto, torna-se necessária a mensuração das perdas endógenas de aminoácidos para se determinar a digestibilidade ileal verdadeira.

Para determinação das perdas endógenas de aminoácidos várias têm sido as técnicas utilizadas e segundo De Lange et al. (1989) existe uma preferência em se utilizar de uma dieta isenta de proteína em relação a técnica de diluição isotópica ou regressão ao consumo zero, isto é devido a maior facilidade e economia além de poder ser aplicada para cada aminoácido. Além disso, mais recentemente Nyachoti et al. (1997) relataram que o fornecimento de uma dieta isenta de proteína ou a utilização da técnica de regressão proporcionam valores similares de perda endógena de aminoácidos em suínos.

Por outro lado, vários fatores podem influenciar as perdas endógenas de aminoácidos, dentre eles tem

\footnotetext{
1 Parte da Dissertação de Doutorado do primeiro autor financiada pela FAPEMIG.

2 Professor do curso de Zootecnia/UNIOESTE. E.mail: pcpozza@hotmail.com

3 Professor do Departamento de Zootecnia/UFV.

4 Professor da UESB.
} 
sido citado o conteúdo de fibra, que pode proporcionar aumento da perda endógena de aminoácidos quando se utiliza dieta isenta de proteína (MariscalLandin et al., 1995). Teoricamente, a fibra dietética pode reduzir a digestibilidade da proteína e de aminoácidos por meio de estímulo da produção de proteína de origem bacteriana, através da adsorsão de aminoácidos e peptídeos para a matriz da fibra e pelo aumento da secreção de proteína endógena (Schulze et al., 1994).

Além disso, tem-se constatado que a inclusão de fibra na dieta resulta em aumento da descamação da mucosa intestinal e incremento da produção de muco, levando ao aumento na perda de aminoácidos endógenos (Scheeman et al., 1982). As secreções do intestino delgado, que incluem a mucina, têm contribuído com grande proporção de secreções endógenas de nitrogênio no intestino delgado (Li et al., 1994). No entanto, em grande número dessas pesquisas a celulose tem sido utilizada como fonte de fibra nas dietas isentas de proteínas, o que nem sempre reflete o tipo de fibra presente nos alimentos em estudo.

A fibra, portanto, é considerada um dos fatores responsáveis pelo aumento da secreção endógena de aminoácidos, tanto pela descamação das células epiteliais, devido à sua natureza física (Shah et al., 1982), quanto pela adsorsão de peptídeos, aminoácidos e enzimas digestivas (Scheeman, 1978), além de estimular a produção de proteína de origem bacteriana (Schulze et al.,1994).

Assim, torna-se necessário avaliar a perda endógena de aminoácidos em função de diferentes níveis de inclusão de fibra a uma dieta isenta de proteína.

\section{Material e Métodos}

O experimento foi conduzido no Setor de Suinocultura do Departamento de Zootecnia da Universidade Federal de Viçosa, Viçosa-MG.

Durante o período experimental, os animais foram alojados em baias de creche, metálicas, suspensas, com pisos plásticos, laterais teladas, dotadas de comedouros semi-automáticos e bebedouros tipo chupeta, localizadas em prédio de alvenaria com piso de concreto, teto de madeira e com janelas basculantes nas laterais.

No interior das instalações, foi utilizado um termômetro de mínima e máxima, à altura dos animais, para que fossem realizadas, duas vezes ao dia, as mensurações das temperaturas mínima e máxima durante o período experimental.

Foram utilizados oito suínos mestiços (Landrace $\mathrm{x}$ Large White), machos e castrados, que foram submetidos à cirurgia para implantação de cânula " $T$ " simples. Após a cirurgia, os animais passaram por um período de 20 dias de recuperação.

Após o período de recuperação, os animais com peso médio inicial de $50,17 \pm 4,10 \mathrm{~kg}$ foram submetidos aos tratamentos, permanecendo durante todo o período experimental nas mesmas instalações.

$\mathrm{O}$ delineamento experimental foi o de blocos ao acaso, com quatro tratamentos e quatro repetições. Os animais foram redistribuídos nos tratamentos, evitando a sua repetição por duas vezes consecutivas. Os tratamentos (T) constaram de uma dieta isenta de proteína, com quatro níveis de inclusão de fibra $(1,00,2,00,3,00$ e 4,00\% de FB e, ou, 1,82, 3,64, 5,46 e $7,28 \%$ de FDN e, ou, 1,50, 3,01, 4,51 e 6,02\% de FDA), formuladas à base de amido de milho, açúcar, óleo, minerais e vitaminas, tendo como fonte de fibra a casca de arroz.

A casca de arroz utilizada foi separada dos grãos de arroz quebrados e das impurezas contidas na palha, por meio de ventilador.

As composições química e energética dos ingredientes utilizados nas rações experimentais encontram-se na Tabela 1. Na Tabela 2, está apresentada a composição dos aminoácidos da casca de arroz.

O conteúdo em aminoácidos e proteína bruta da casca de arroz, foi considerado como totalmente indigestível, sendo então subtraídos dos valores de perda endógena.

As rações experimentais (Tabela 3) continham 0,5\% de óxido crômico $\left(\mathrm{Cr}_{2} \mathrm{O}_{3}\right)$, utilizado como indicador na determinação da digestibilidade.

A quantidade de ração fornecida diariamente a cada animal foi calculada com base no tamanho metabólico $\left(\mathrm{kg}^{0,75}\right)$. Para evitar perdas e facilitar a ingestão, as rações foram umedecidas e fornecidas duas vezes ao dia (7 e $19 \mathrm{~h}$ ).

Foi adotado o período de cinco dias de adaptação dos animais aos tratamentos e um dia de coleta de digesta, que tinha início às $7 \mathrm{~h}$ e término às $7 \mathrm{~h}$ do dia seguinte, em intervalos de três horas.

A digesta foi coletada em sacos de polietileno, presos à cânula, e posteriormente colocadas em sacos plásticos, identificadas e armazenadas em congelador $\left(-5^{\circ} \mathrm{C}\right)$, até o final do período de coleta. Ao 
Tabela 1 - Composição química e energética dos ingredientes utilizados nas rações experimentais

Table 1 - Chemistry and energetic composition of ingredients used in the experimental rations

\begin{tabular}{|c|c|c|c|c|c|c|}
\hline & $\begin{array}{c}\text { Casca de arroz } \\
\text { Rice peel }\end{array}$ & $\begin{array}{l}\text { Açúcar } \\
\text { Sugar }\end{array}$ & $\begin{array}{l}\text { Amido } \\
\text { Starch }\end{array}$ & $\begin{array}{c}\text { Óleo } \\
\text { Oil }\end{array}$ & $\begin{array}{l}\text { Calcário } \\
\text { Limestone }\end{array}$ & $\begin{array}{l}\text { Fosfato bicálcico } \\
\text { Dicalcium phosphate }\end{array}$ \\
\hline Energia digestível $(\mathrm{kcal} / \mathrm{kg})^{2}$ & - & 4.124 & 3.708 & 7.956 & - & - \\
\hline Digestible energy & & & & & & \\
\hline Matéria seca $(\%)^{1}$ & 90,50 & 99,65 & 88,70 & - & - & - \\
\hline Dry matter & & & & & & \\
\hline Proteína bruta (\%) & 1,75 & 0,05 & 0,49 & - & - & - \\
\hline $\begin{array}{l}\text { Crude protein } 1 \\
\text { Cálcio }(\%)\end{array}$ & $0,08^{3}$ & - & - & - & $37,70^{2}$ & $22,61^{2}$ \\
\hline $\begin{array}{l}\text { Calcium } \\
\text { Fósforo total (\%) }\end{array}$ & $0,14^{3}$ & - & - & - & - & $17,03^{2}$ \\
\hline $\begin{array}{l}\text { Total phosphorus } \\
\text { Fibra bruta (\%) } \\
\text { Crude fiber }\end{array}$ & $38,18^{1}$ & - & - & - & - & - \\
\hline $\begin{array}{l}\text { Fibra detergente neutro }(\%) \\
\text { Neutral detergent fiber }\end{array}$ & $69,47^{1}$ & - & - & - & - & - \\
\hline $\begin{array}{l}\text { Fibra detergente ácido (\%) } \\
\text { Acid detergent fiber }\end{array}$ & $57,41^{1}$ & - & - & - & - & - \\
\hline $\begin{array}{l}\text { Hemicelulose }(\%) \\
\text { Hemicellulose }\end{array}$ & $12,06^{4}$ & - & - & - & - & - \\
\hline $\begin{array}{l}\text { Lignina }(\%) \\
\text { Lignin }\end{array}$ & $28,70^{1}$ & - & - & - & - & - \\
\hline
\end{tabular}

1 Valores médios obtidos por análises realizadas no Laboratório de Nutrição Animal (UFV).

${ }^{2}$ Valores calculados das Tabelas Brasileiras de Composição de Alimentos e Exigências de Aves e Suínos (Rostagno et al., 1992).

${ }^{3}$ Valores obtidos da Tabela de Composição Química e Valores Energéticos de Alimentos para Suínos e Aves (EMBRAPA, 1991).

${ }^{4}$ Calculado segundo Silva et al. (1990).

${ }_{1}^{1}$ Average values obtained by analysis realized at Animal Nutrition Laboratory (UFV)

2 Calculated values from Tabelas Brasileiras de Composição de Alimentos e Exigências de Aves e Suínos (Rostagno et al., 1992).

${ }^{3}$ Values obtained from Tabela de Composição Química e Valores Energéticos de Alimentos para Suínos e Aves (EMBRAPA, 1991).

${ }^{4}$ Calculated according toSilva et al. (1990)

final desse período as amostras, compostas por animal, foram descongeladas, pesadas, homogeneizadas e liofilizadas.

Foram determinados os teores de matéria seca, proteína bruta e crômio das digestas e rações experimentais. Estas análises foram realizadas no Laboratório de Nutrição Animal do Departamento de Zootecnia da Universidade Federal de Viçosa, de acordo com as técnicas descritas por SILVA (1990).

A composição em aminoácidos, das digestas e rações, foram realizadas no Laboratório de Nutrição Animal do Departamento de Zootecnia da Universidade Federal de Viçosa e na Ajinomoto Biolatina Ind. e Com. Ltda.

Os dados foram submetidos às análises estatísticas, utilizando o programa SAEG, desenvolvido pela UFV (1999). As estimativas das perdas endógenas de cada aminoácidos foi realizada com o uso do modelo linear e, ou, quadrático, e na análise de variância adotou-se o consumo de matéria seca como co-variável.
Tabela 2 - Composição em aminoácidos da casca de arroz, em percentagem 1

Table 2 - Amino acid composition of rice peel, in percentage

\begin{tabular}{lc}
\hline $\begin{array}{l}\text { Aminoácidos essenciais (\%) } \\
\text { Essential amino acid }\end{array}$ & $\begin{array}{c}\text { Casca de arroz } \\
\text { Rice peel }\end{array}$ \\
\hline Arginina (Arginine) & 0,056 \\
Histidina (Histdine) & 0,028 \\
Isoleucina (Isoleucine) & 0,050 \\
Leucina (Leucine) & 0,110 \\
Lisina (Lysine) & 0,069 \\
Metionina (Methionine) & 0,021 \\
Fenilalanina (Phenylalanine) & 0,066 \\
Treonina (Threonine) & 0,070 \\
Valina(Valine) & 0,091 \\
Não-essenciais (\%) (Non essential) & \\
Alanina (Alanine) & 0,105 \\
Ácido aspártico (Aspartic acid) & 0,139 \\
Ácido glutâmico (Glutamic acid) & 0,180 \\
Cistina (Cystine) & 0,023 \\
Glicina(Glycine) & 0,083 \\
Serina(Serine) & 0,071 \\
Tirosina (Tyrosine) & 0,017 \\
\hline
\end{tabular}

${ }^{1}$ Análises realizadas nos laboratórios da AJINOMOTO BIOLATINA In. e Com. Ltda., São Paulo-SP e de Nutrição Animal (UFV).

${ }^{1}$ Analyses were performed at AJINOMOTO BIOLATINA In. e Com. Ltda., São Paulo-SP and Animal Nutrition laboratory (UFV). 
Tabela 3 - Composição centesimal das rações experimentais

Table 3 - Centesimal composition of experimental rations

\begin{tabular}{|c|c|c|c|c|}
\hline \multirow[t]{2}{*}{$\begin{array}{l}\text { Ingredientes (\%) } \\
\text { Ingredient (\%) }\end{array}$} & \multicolumn{4}{|c|}{$\begin{array}{c}\text { Tratamentos } \\
\text { Treatments } \\
\end{array}$} \\
\hline & 1 & 2 & 3 & 4 \\
\hline $\begin{array}{l}\text { Casca de arroz } \\
\text { Rice peel }\end{array}$ & 2,62 & 5,24 & 7,86 & 10,48 \\
\hline $\begin{array}{l}\text { Açúcar } \\
\text { Sugar }\end{array}$ & 10,00 & 10,00 & 10,00 & 10,00 \\
\hline $\begin{array}{l}\text { Amido } \\
\text { Starch }\end{array}$ & 82,28 & 79,68 & 77,08 & 74,46 \\
\hline $\begin{array}{l}\text { Óleo } \\
\text { Oil }\end{array}$ & 1,00 & 1,00 & 1,00 & 1,00 \\
\hline $\begin{array}{l}\text { Fosfato bicálcico } \\
\text { Dicalcium phosphate }\end{array}$ & 2,99 & 2,97 & 2,96 & 2,95 \\
\hline $\begin{array}{l}\text { Sal } \\
\text { Salt }\end{array}$ & 0,35 & 0,35 & 0,35 & 0,35 \\
\hline $\begin{array}{l}\text { Suplem. mineral } \stackrel{1 /}{ } \\
\text { Mineral supplement }\end{array}$ & 0,10 & 0,10 & 0,10 & 0,10 \\
\hline $\begin{array}{l}\text { Suplem. vitamínico } 2 \text { / } \\
\text { Vitamin suplement }\end{array}$ & 0,05 & 0,05 & 0,05 & 0,05 \\
\hline $\begin{array}{l}\text { Antibiótico } \\
\text { Antibiotic }\end{array}$ & 0,10 & 0,10 & 0,10 & 0,10 \\
\hline $\begin{array}{l}\text { Antioxidante } \\
\text { Antioxidant }\end{array}$ & 0,01 & 0,01 & 0,01 & 0,01 \\
\hline $\begin{array}{l}\text { Óxido Crômico } \\
\text { Chromic oxide } \\
\text { Composição calculada } \\
\text { Calculated composition }\end{array}$ & 0,50 & 0,50 & 0,50 & 0,50 \\
\hline $\begin{array}{l}\text { Proteína bruta }(\%) \\
\text { Crude protein }\end{array}$ & 0,45 & 0,48 & 0,52 & 0,55 \\
\hline $\begin{array}{l}\text { Energia digestível } \\
(\mathrm{kcal} / \mathrm{kg})\end{array}$ & 3.541 & 3.445 & 3.348 & 3.251 \\
\hline $\begin{array}{l}\text { Digestible energy } \\
\text { Cálcio (\%) }\end{array}$ & 0,68 & 0,68 & 0,68 & 0,68 \\
\hline $\begin{array}{l}\text { Calcium } \\
\text { Fósforo total }(\%)\end{array}$ & 0,51 & 0,51 & 0,51 & 0,51 \\
\hline $\begin{array}{l}\text { Total phosphorus } \\
\text { Fibra bruta(\%) }\end{array}$ & 1,000 & 2,000 & 3,000 & 4,000 \\
\hline Crude fiber & & & & \\
\hline $\begin{array}{l}\mathrm{FDN}(\%) \\
N D F\end{array}$ & 1,820 & 3,640 & 5,460 & 7,280 \\
\hline $\begin{array}{l}\text { FDA }(\%) \\
A D F\end{array}$ & 1,504 & 3,008 & 4,512 & 6,016 \\
\hline $\begin{array}{l}\text { Hemicelulose }(\%) \\
\text { Hemicellulose }\end{array}$ & 0,316 & 0,632 & 0,948 & 1,264 \\
\hline $\begin{array}{l}\text { Lignina (\%) } \\
\text { Lignin }\end{array}$ & 0,752 & 1,504 & 2,256 & 3,008 \\
\hline
\end{tabular}

${ }^{1}$ Conteúdo/kg (Content/kg): ferro(iron), $100 \mathrm{~g}$; cobre(copper), $10 \mathrm{~g}$; cobalto (cobalt), $1 \mathrm{~g}$; manganês (manganese), $40 \mathrm{~g}$; zinco (zinc), 100 g; iodo(iodine), $1,5 \mathrm{~g}$; e veículo q.s.p.(q.s.p. vehicle) $500 \mathrm{~g}$.

${ }^{2}$ Conteúdo $/ \mathrm{kg}$ (Content $/ \mathrm{kg}$ ): vit. A, 10.000 .000 U.I.; vit $\mathrm{D}_{3}, 1.500 .000$ U.I.; vit. E, 30.000 U.I.; vit $B_{1}-2,0$ g; vit $B_{2}-5,0$ g; vit. $B_{6}-3,0$ g; vit $\mathrm{B}_{12}-30.000 \mathrm{mcg}$; ácido nicotínico (nicotinic acid) $30.000 \mathrm{mcg}$; ácido pantotênico (pantotenic acid), 12.000 mcg; Vit. $\mathrm{K}_{3}, 2.000$ $\mathrm{mg}$; ácido fólico(folic acid), $800 \mathrm{mg}$; biotina(biotin), $100 \mathrm{mg}$; selênio(selenium) $300 \mathrm{mg}$; e veículo q.s.p.(q.s.p. vehicle) $1.000 \mathrm{~g}$.

\section{Resultados e Discussão}

As médias das temperaturas máxima e mínima do interior das instalações foram de $26,00 \pm 2,19^{\circ} \mathrm{C}$ e $21,35 \pm 1,69^{\circ} \mathrm{C}$, respectivamente.

As perdas ileais endógenas dos aminoácidos estudados, em função dos níveis de fibra da dieta isenta de proteína, estão apresentadas na Tabela 4. Com exceção do aminoácido glicina, a perda endógena dos demais aminoácidos aumentou $(\mathrm{P}<0,05)$ de forma linear, à medida que o nível de fibra da dieta se elevou.

Observou-se também grande variação entre as perdas endógenas de cada aminoácido, dentro do mesmo tratamento, tendo sido observada variação de 0,05 a 0,42 mg de aminoácido endógeno por grama de dieta isenta de proteína (DIP) consumida, para a metionina e o ácido glutâmico, respectivamentes, no tratamento 1 . No tratamento 4, a metionina continuou apresentando o menor valor de perda endógena de aminoácidos $(0,09$ $\mathrm{mg} / \mathrm{g}$ DIP consumida), entretanto a alanina demonstrou a maior perda endógena $(0,82 \mathrm{mg} / \mathrm{g}$ DIP consumida). Essas diferenças entre o conteúdo de aminoácidos ileais endógenos, segundo Fan et al. (1995), podem ser atribuídas, principalmente, às diferenças nas concentrações das várias secreções endógenas do trato digestivo.

O perfil de excreção endógena de aminoácidos assemelha-se ao obtido por Serrano (1989), que trabalhando com suínos anastomosados, com peso médio inicial de $31,34 \mathrm{~kg}$, utilizando uma dieta isenta de proteína e tendo como fonte de fibra a casca de arroz $(1,49 \%)$ e o sabugo de milho (1,49\%), obteve, dentre os aminoácidos estudados, menor excreção endógena para a metionina e maior excreção para o ácido glutâmico, sendo de 0,1751 e $0,8634 \mathrm{mg} / \mathrm{g}$ de DIP consumida, respectivamente, valores estes superiores aos obtidos no presente estudo. Por outro lado, Pozza (1998), trabalhando com suínos anastomosados, com peso médio inicial de $22,0 \mathrm{~kg}$, e uma dieta isenta de proteína com $2,36 \%$ de fibra bruta, proveniente da inclusão de casca de arroz, encontrou menor excreção endógena para a cistina $(0,05 \mathrm{mg} / \mathrm{g}$ de DIP consumida) e maior excreção para o ácido glutâmico $(0,53 \mathrm{mg} / \mathrm{g}$ de DIP consumida), em relação aos demais aminoácidos avaliados.

Além de a metionina ter apresentado a menor perda endógena, dentre todos os aminoácidos estudados, em todos os tratamentos pode-se observar também que a contribuição endógena não só da metionina, como também da cistina não foram muito expressi- 
Tabela 4 - Valores médios de aminoácidos endógenos ileais (AEI) ${ }^{1}$, determinados utilizando uma dieta isenta de proteína (DIP) com diferentes níveis de fibra.

Table 4 - Average values of ileal endogenous amino acids $(I E A A)^{1}$ determined by using a free protein diet (FPD) with different fiber levels

\begin{tabular}{|c|c|c|c|c|c|}
\hline \multirow[t]{2}{*}{$\begin{array}{l}\text { Aminoácidos Essenciais } \\
\text { Essential amino acid }\end{array}$} & \multicolumn{5}{|c|}{$\begin{array}{c}\text { AEI (mg/g DIP consumida) } \\
\text { IEAA, } m g / g \text { FPD intake }\end{array}$} \\
\hline & $\mathrm{T} 1$ & $\mathrm{~T} 2$ & T3 & $\mathrm{T} 4$ & $\mathrm{CV} \%$ \\
\hline Arginina $^{2}$ & 0,13 & 0,16 & 0,22 & 0,26 & 14,23 \\
\hline $\begin{array}{l}\text { Histidina }^{2} \\
\text { Histidine }^{2}\end{array}$ & 0,06 & 0,07 & 0,11 & 0,13 & 12,64 \\
\hline $\begin{array}{l}\text { Isoleucina } 2,4 \\
\text { Isoleucine } e^{2,4}\end{array}$ & 0,22 & 0,21 & 0,28 & 0,35 & 7,83 \\
\hline $\begin{array}{l}\text { Leucina }^{2} \\
\text { Leucine }^{2}\end{array}$ & 0,31 & 0,32 & 0,42 & 0,53 & 6,99 \\
\hline $\begin{array}{l}\text { Lisina }^{2} \\
\text { Lysine }^{2}\end{array}$ & 0,18 & 0,33 & 0,45 & 0,58 & 8,66 \\
\hline $\begin{array}{l}\text { Metionina } 2 \\
\text { Methionine }^{2}\end{array}$ & 0,05 & 0,06 & 0,06 & 0,09 & 13,93 \\
\hline $\begin{array}{l}\text { Fenilalanina }^{2} \\
\text { Phenylalanine }^{2}\end{array}$ & 0,12 & 0,19 & 0,28 & 0,33 & 9,92 \\
\hline $\begin{array}{l}\text { Treonina } 2 \\
\text { Threonine }^{2}\end{array}$ & 0,27 & 0,32 & 0,36 & 0,43 & 10,78 \\
\hline $\begin{array}{l}\text { Valina } \\
\text { Valine }^{2,4}\end{array}$ & 0,33 & 0,33 & 0,40 & 0,54 & 7,95 \\
\hline $\begin{array}{l}\text { Não-essenciais } \\
\text { Nonessentials }\end{array}$ & & & & & \\
\hline $\begin{array}{l}\text { Alanina } 2,4 \\
\text { Alanine }^{2,4}\end{array}$ & 0,41 & 0,44 & 0,52 & 0,82 & 11,25 \\
\hline $\begin{array}{l}\text { Ac. Aspártico } \\
\text { Aspartic acid }^{2}\end{array}$ & 0,38 & 0,44 & 0,50 & 0,69 & 17,70 \\
\hline $\begin{array}{l}\text { Ac. Glutâmico }{ }^{2} \\
\text { Glutamic acid }^{2}\end{array}$ & 0,42 & 0,47 & 0,60 & 0,78 & 11,00 \\
\hline $\begin{array}{l}\text { Cistina }^{2} \\
\text { Cystine }^{2}\end{array}$ & 0,12 & 0,13 & 0,14 & 0,18 & 11,42 \\
\hline Glicina & 0,42 & 0,51 & 0,48 & 0,54 & 10,17 \\
\hline $\begin{array}{l}\text { Serina }^{2} \\
\text { Serine }^{2}\end{array}$ & 0,18 & 0,19 & 0,26 & 0,32 & 10,97 \\
\hline $\begin{array}{l}\text { Tirosina } \\
\text { Tyrosine } \\
\text { Ty }\end{array}$ & 0,10 & 0,11 & 0,17 & 0,16 & 17,85 \\
\hline
\end{tabular}

1 Dados expressos na base da matéria seca (Expressed in dry matter basis).

2 Efeito linear $(P<0,01)$ (Linear effect, $(P<.01)$.

3 Efeito linear $(P<0,05)$ (Linear effect, $P<.05)$.

${ }^{4}$ Efeito quadrático $(P<0,05)$ (Quadratic effect, $\left.P<.05\right)$.

vas, devendo ser ressaltado que houve maior perda endógena ileal para a cistina do que para a metionina. Tal resultado pode ser explicado, em parte, pelo fato de o conteúdo de aminoácidos sulfurosos, tanto na camada de mucina quanto no suco pancreático, ser freqüentemente menor, comparado aos demais aminoácidos, e de a cistina apresentar maior contribuição endógena em ambas as secreções, comparada à metionina (Pöhland et al., 1993).

Observou-se diferença significativa dos valores de perda endógena de treonina $(\mathrm{P}<0,01)$, que, de acordo com Grala et al. (1998), é devida ao aumento de glicoproteínas provenientes do muco intestinal, que possuem grande quantidade de treonina.

Os resultados significativos $(\mathrm{P}<0,01)$ obtidos para os ácidos aspártico e glutâmico também podem ser devido ao aumento das descamações intestinais, proporcionado pelo aumento dos níveis de fibra, pois Neutra \& Forstner (1987) relataram que as glicoproteínas da mucina possuem expressiva quantidade desses aminoácidos, assim como de treonina. Os elevados valores de perda endógena, obtidos para os ácidos aspártico e glutâmico, podem estar associados a uma relativa proporção destes aminoácidos no suco 
pancreático de suínos (Pöhland et al., 1993), além de sua contribuição na camada de mucina, e, no caso da leucina, ter apresentado diferença significativa $(\mathrm{P}<0,01)$, o que pode ser devido também às secreções pancreáticas, pois segundo esses autores o suco pancreático de suínos apresenta expressiva quantidade de leucina.

O resultado de perda endógena obtido para glicina $(\mathrm{P}>0,05)$ não condiz com os resultados encontrados por De Lange et al. (1989), que observaram diferenças na perda endógena ileal da glicina ao suplementar pectina e celulose à dieta isenta de proteína.

Nas Tabelas 5 e 6, estão apresentadas as equações de regressão, em função dos níveis de FB, FDN e FDA, respectivamente.

Pode-se observar que a maioria dos efeitos significativos encontrados foram lineares, devendo ser ressaltado que para isoleucina, valina e alanina foram encontrados efeitos lineares e quadráticos (Tabelas 5 e 6). Resultados semelhantes foram obtidos por De Lange et al. (1989), que encontraram diferenças significativas entre os valores de perda endógena de todos os aminoácidos essenciais e não-essenciais, expressos em função da porcentagem da proteína bruta endógena, quando avaliaram a inclusão de pectina, celulose e óleo de canola à dieta isenta de proteína, observando ainda que o efeito da pectina purificada sobre a perda ileal endógena de aminoácidos foi maior que o da celulose purificada. Este aumento das perdas endógenas de aminoácidos, em função da adição de fibra à dieta, pode ser atribuído, entre outros, ao aumento na descamação das células epiteliais, por causa de sua natureza física (Shah et al., 1982), como também pela adsorsão de peptídeos, aminoácidos e enzimas digestivas (Scheeman, 1978). Por outro lado, Sauer et al. (1991) não encontraram diferenças, com exceção de dois aminoácidos, na digestibilidade ileal aparente de aminoácidos quando foi utilizado $10 \%$ de Alphafloc ou palha de cevada em uma dieta à base de amido de milho e farelo de soja. Posteriormente, Leterme et al. (1992), trabalhando com

Tabela 5 - Estimativas das perdas endógenas de aminoácidos essenciais em função dos conteúdos de fibra bruta (FB), fibra em detergente neutro (FDN) e fibra em detergente ácido (FDA) da dieta isenta de proteína, através de modelos de regressão polinomial

Table 5 - Estimates of the essentials amino acids endogenous losses in function of the crude fiber(CF), neutral detergent fiber (NDF) and acid detergent fiber (ADF) content of the free protein diet, through polinomial regression models

\begin{tabular}{|c|c|c|c|c|}
\hline $\begin{array}{l}\text { Aminoácidos } \\
\text { essenciais } \\
\text { Essential amino acid }\end{array}$ & $\begin{array}{c}\text { Equações de } \\
\text { regressão }(\mathrm{FB}) \\
\text { Regression } \\
\text { equations }(C F) \\
\end{array}$ & $\begin{array}{c}\text { Equações de } \\
\text { regressão (FDN) } \\
\text { Regression } \\
\text { equations (NDF) }\end{array}$ & $\begin{array}{c}\text { Equações de } \\
\text { regressão (FDA) } \\
\text { Regression } \\
\text { equations }(A D F) \\
\end{array}$ & $\mathrm{R}^{2}$ \\
\hline Arginina $^{1}$ & $\hat{Y}=0,0805+0,0445 \mathrm{X}$ & $\hat{Y}=0,0805+0,0245 \mathrm{X}$ & $\hat{Y}=0,0805+0,0295 \mathrm{X}$ & 0,77 \\
\hline \multicolumn{5}{|l|}{ Arginine } \\
\hline Histidina $^{1}$ & $\hat{Y}=0,0221+0,0279 \mathrm{X}$ & $\hat{Y}=0,0221+0,0153 \mathrm{X}$ & $\hat{Y}=0,0221+0,0185 \mathrm{X}$ & 0,85 \\
\hline \multicolumn{5}{|l|}{ Histidine } \\
\hline Isoleucina ${ }^{1,2}$ & $\hat{Y}=0,1463+0,0464 \mathrm{X}$ & $\hat{Y}=0,1463+0,0255 \mathrm{X}$ & $\hat{Y}=0,1463+0,0308 \mathrm{X}$ & 0,72 \\
\hline Isoleucine & $\hat{Y}=0,2495-0,0568 \mathrm{X}+0,0206 \mathrm{X}^{2}$ & $\hat{Y}=0,2495-0,0312 \mathrm{X}+0,0062 \mathrm{X}^{2}$ & $\hat{Y}=0,2495-0,0378 \mathrm{X}+0,0091 \mathrm{X}^{2}$ & 0,83 \\
\hline Leucina $^{1}$ & $\hat{Y}=0,2028+0,0759 \mathrm{X}$ & $\hat{Y}=0,2028+0,0417 \mathrm{X}$ & $\hat{Y}=0,2028+0,0505 \mathrm{X}$ & 0,82 \\
\hline \multicolumn{5}{|l|}{ Leucine } \\
\hline Lisina $^{1}$ & $\hat{Y}=0,0575+0,1316 \mathrm{X}$ & $\hat{Y}=0,0575+0,0723 \mathrm{X}$ & $\hat{Y}=0,0575+0,0875 \mathrm{X}$ & 0,96 \\
\hline \multicolumn{5}{|l|}{ Lysine } \\
\hline Metionina $^{1}$ & $\hat{Y}=0,0343+0,0124 \mathrm{X}$ & $\hat{Y}=0,0343+0,0068 \mathrm{X}$ & $\hat{Y}=0,0343+0,0083 \mathrm{X}$ & 0,63 \\
\hline \multicolumn{5}{|l|}{ Methionine } \\
\hline Fenilalanina $^{1}$ & $\hat{Y}=0,0500+0,0715 \mathrm{X}$ & $\hat{Y}=0,0500+0,0393 \mathrm{X}$ & $\hat{Y}=0,0500+0,0475 \mathrm{X}$ & 0,90 \\
\hline \multicolumn{5}{|l|}{ Phenylalanine } \\
\hline Treonina $^{1}$ & $\hat{Y}=0,2133+0,0533 \mathrm{X}$ & $\hat{Y}=0,2133+0,0293 \mathrm{X}$ & $\hat{Y}=0,2133+0,0354 \mathrm{X}$ & 0,72 \\
\hline \multicolumn{5}{|l|}{ Threonine } \\
\hline Valina $^{1,2}$ & $\hat{Y}=0,2246+0,0701 \mathrm{X}$ & $\hat{Y}=0,2246+0,0385 \mathrm{X}$ & $\hat{Y}=0,2246+0,0466 \mathrm{X}$ & 0,70 \\
\hline Valine & $\hat{Y}=0,4034-0,1087 \mathrm{X}+0,0358 \mathrm{X}^{2}$ & $\hat{Y}=0,4034-0,0597 \mathrm{X}+0,0108 \mathrm{X}^{2}$ & $\hat{Y}=0,4034-0,0722 \mathrm{X}+0,0158 \mathrm{X}^{2}$ & 0,85 \\
\hline
\end{tabular}

1 Efeito linear $(P<0,01)$ (Linear effect $[P<.01])$.

2 Efeito quadrático $(P<0,05)$ (Quadratic effect $[P<.05])$.

R. Bras. Zootec., v.32, n.6, p.1354-1361, 2003 
Tabela 6 - Estimativas das perdas endógenas de aminoácidos não essenciais em função dos conteúdos de fibra bruta (FB), fibra em detergente neutro (FDN) e fibra em detergente ácido (FDA) da dieta isenta de proteína, através de modelos de regressão polinomial

Table 6 - Estimates of the nonessentials amino acids endogenous losses in function of the crude fiber(CF), neutral detergent fiber (NDF) and acid detergent fiber (ADF) content of the free protein diet, through polinomial regression models

\begin{tabular}{|c|c|c|c|c|}
\hline $\begin{array}{l}\text { Aminoácidos } \\
\text { essenciais } \\
\text { Essential amino acid }\end{array}$ & $\begin{array}{l}\text { Equações de } \\
\text { regressão (FB) } \\
\text { Regression } \\
\text { equations }(C F)\end{array}$ & $\begin{array}{c}\text { Equações de } \\
\text { regressão (FDN) } \\
\text { Regression } \\
\text { equations (NDF) }\end{array}$ & $\begin{array}{c}\text { Equações de } \\
\text { regressão (FDA) } \\
\text { Regression } \\
\text { equations }(A D F)\end{array}$ & $\mathrm{R}^{2}$ \\
\hline Alanina ${ }^{1,3}$ & $\hat{Y}=0,2185+0,1321 \mathrm{X}$ & $\hat{Y}=0,2185+0,0726 \mathrm{X}$ & $\hat{Y}=0,2185+0,0878 \mathrm{X}$ & \\
\hline Alanine & $\hat{Y}=0,5579-0,2072 \mathrm{X}+0,0679 \mathrm{X}^{2}$ & $\hat{Y}=0,5579-0,1138 \mathrm{X}+0,0205 \mathrm{X}^{2}$ & $\hat{Y}=0,5579-0,1378 \mathrm{X}+0,0300 \mathrm{X}^{2}$ & 0,85 \\
\hline $\begin{array}{l}\text { Ac. aspártico }{ }^{1} \\
\text { Asparticacid }\end{array}$ & $\hat{Y}=0,2493+0,1010 \mathrm{X}$ & $\hat{Y}=0,2493+0,0555 \mathrm{X}$ & $\hat{Y}=0,2493+0,0971 \mathrm{X}$ & 0,58 \\
\hline $\begin{array}{l}\text { Ac. glutâmico }{ }^{1} \\
\text { Glutamicacid }\end{array}$ & $\hat{Y}=0,2687+0,1110 \mathrm{X}$ & $\hat{Y}=0,2687+0,0659 \mathrm{X}$ & $\hat{Y}=0,2687+0,0798 \mathrm{X}$ & 0,78 \\
\hline $\begin{array}{l}\text { Cistina }^{1} \\
\text { Cystine }\end{array}$ & $\hat{Y}=0,0952+0,0194 \mathrm{X}$ & $\hat{Y}=0,0952+0,0106 \mathrm{X}$ & $\hat{Y}=0,0952+0,0129 \mathrm{X}$ & 0,57 \\
\hline $\begin{array}{l}\text { Serina }{ }^{1} \\
\text { Serine }\end{array}$ & $\hat{Y}=0,1210+0,0473 \mathrm{X}$ & $\hat{Y}=0,1210+0,0260 \mathrm{X}$ & $\hat{Y}=0,1210+0,0314 \mathrm{X}$ & 0,75 \\
\hline $\begin{array}{l}\text { Tirosina }^{2} \\
\text { Tirosine }\end{array}$ & $\hat{Y}=0,0784+0,0224 \mathrm{X}$ & $\hat{Y}=0,0784+0,0123 \mathrm{X}$ & $\hat{Y}=0,0784+0,0149 \mathrm{X}$ & 0,40 \\
\hline
\end{tabular}

1 Efeito linear $(\mathrm{P}<0,01)$ (Linear effect $(P<.01)$.

2 Efeito quadrático $(P<0,05)$ (Quadratic effect $(P<.05)$.

${ }^{3}$ Efeito quadrático $(\mathrm{P}<0,05)$ (Quadratic effect $\left.[P<.05]\right)$.

suínos anastomosados, com peso médio inicial de $64 \mathrm{~kg}$, também não encontraram efeitos significativos dos níveis de fibra, adicionados à dieta isenta de proteína, sobre a perda endógena de aminoácidos, no entanto eles utilizaram quatro níveis de inclusão de celulose de madeira $(30,60,90$ e $120 \mathrm{~g} / \mathrm{kg}$ ) como fonte de fibra.

As divergências entre os resultados obtidos no presente trabalho e os da literatura consultada (Sauer et al., 1991; Leterme et al., 1992) podem ser atribuídas à composição da fibra utilizada (De Lange et al., 1989) nos diferentes trabalhos. A casca de arroz, utilizada como fonte de fibra no presente trabalho, possuía, além de celulose, $4,77 \%$ de hemicelulose e $28,70 \%$ de lignina, e, por outro lado, o principal componente fibroso no Alphafloc, na palha de cevada e na celulose de madeira é a celulose. Segundo Leterme et al. (1992), a celulose possui baixa capacidade de adsorção, não podendo ser comparada com outros materiais fibrosos, como a fibra da alfafa e lignina. Além disto, Mitaru et al. (1984) relataram que a fibra é capaz de adsorver aminoácidos e peptídeos, o que prejudica a absorção destes, sendo a intensidade da adsorsão dependente do grau de lignificação. Segundo Shah et al. (1982), esta capacidade de adsorção de aminoácidos pode ser devido às propriedades da lignina em formar ligações hidrofóbicas com aminoácidos.
Por outro lado, no trabalho realizado por Leterme et al. (1992) foi utilizada a técnica de anastomose íleo retal, o que também pode ter colaborado com as diferenças observadas entre os resultados obtidos no presente trabalho e os observados pelos autores supracitados, pois Nyachoti et al. (1997) relataram que o impacto da anastomose íleo retal sobre a fisiologia e nutrição do animal pode exercer alguns efeitos, particularmente o papel funcional do intestino delgado pode ser alterado em virtude da ausência do cólon. Isto pode alterar a digestibilidade se comparada com a utilização de outros métodos (Fuller, 1991). Além disso, a preservação do papel funcional do esfíncter íleo-cecal, descrito em determinadas técnicas, permite a amostragem da digesta de acordo com o seu fluxo normal no intestino grosso, possibilitando assim a mensuração da digestibilidade ileal de nutrientes ao se utilizar dietas com altos níveis de fibra que não foi finamente moída (Sauer \& Ozimeck, 1986).

Os resultados obtidos, em parte, se assemelham aos encontrados por Schulze et al. (1994), que observaram redução das perdas endógenas de nitrogênio à medida que o conteúdo de FDN da dieta foi reduzido. Os autores associaram a redução das perdas endógenas de nitrogênio à redução do FDN da dieta.

$\mathrm{O}$ aumento das secreções endógenas em função da inclusão de fibra à dieta isenta de proteína, obser- 
vado neste estudo, pode ser também devido ao um aumento das secreções intestinais, uma vez que Nyachoti et al. (1997), em sua revisão, relataram que as secreções do suco pancreático no muco aumentam com o incremento do consumo de vários tipos de fibra da dieta.

A fibra, portanto, pode ser responsável pelo aumento da secreção endógena de aminoácidos, tanto pela descamação das células epiteliais, devido à sua natureza física (Shah et al., 1982), quanto pela adsorsão de peptídeos, aminoácidos e enzimas digestivas (Scheeman, 1978), reduzindo então a sua digestão e absorção, apesar de ainda não haver evidências claras na literatura de qual dos dois é mais importante (Nyachoti et al., 1996). Dessa forma, na determinação das perdas ileais endógenas de aminoácidos, ao utilizar uma dieta isenta de proteína, deve-se levar em consideração não só a quantidade de fibra adicionada, mas também o tipo de fibra a ser utilizada.

\section{Conclusões}

O aumento dos níveis de fibra, provenientes da inclusão da casca de arroz à dieta isenta de proteína, resultou em aumento da perda endógena dos aminoácidos estudados, com exceção da glicina.

\section{Literatura Citada}

DE LANGE, C.F.M.; SAUER, W.C.; MOSENTHIN, R. et al. The effect of feeding different protein-free diets on the recovery and amino acid composition of endogenous protein collected from the distal ileum and feces in pigs. Journal of Animal Science, v.67, p.746-754, 1989.

EMPRESA DE PESQUISA AGROPECUÁRIA BRASILEIRA. Centro Nacional de Pesquisa de Suínos e Aves (CNPSA) EMBRAPA-CNPSA. Tabela de composição química e valores energéticos de alimentos para suínos e aves. 3.ed. Concórdia-SC, EMBRAPA-CNPSA, 1991. 97p. (Documento 19).

FAN, M.Z.; SAUER, W.C.; MCBURNEY, M.I. Estimation by regression analisys of endogenous amino acid levels in digesta collected from the distal ileum of pigs. Journal of Animal Science, v.73, p.2319-2328, 1995.

FULLER, M.F. Methodologies for the measurement of digestion. In: INTERNATIONAL SYMPOSIUM ON DIGESTIVE PHYSIOLOGY IN PIGS, 1991, 5., Wageningen. Proceedings...Wageningen: Netherlands, 1991. p. 24-26.

GRALA, W.; VERSTEGEN, M.W.A.; JANSMAN, A.J.M. et al. Ileal apparent protein and amino acid digestibilities and endogenous nitrogen losses in pigs fed soybean a rapeseed products. Journal of Animal Science, v.76, p.557-568, 1998.

LETERME, P.; PIRARD, L.; THÉWIS, A. A note on the effect of wood cellulose level in protein-free diets on the recovery and amino acid composition of endogenous protein collected from the ileum in pigs. Animal Production, v.54, p.163$165,1992$.

LI, S.; SAUER, W.C.; HARDIN, R.T. Effect of dietary fibre level on amino acid digestibility in young pigs. Canadian Journal of Animal Science, v.74, p.327-333, 1994.

MARISCAL-LANDIN, G.; SÈVE, B.; COLLÉAUX, Y. et al. Endogenous amino nitrogen, collected from pigs with endto-end ileorectal anastomosis is affected by the method of estimation and altered by dietary fiber. Journal Nutrition, v.125, p.136-146, 1995.

MITARU, B.N.; BLAIR, R.; REICHERT, R.D. et al. 1984. Dark and yellow rapeseed hulls, soybean hulls and a purified fiber source: their effect on dry matter, energy, protein and amino acid digestibilities in cannulated pigs. Journal of Animal Science, v.59, p.510-1518.

NEUTRA, M.R.; FORSTNER, J.F. Physiology of the gastrintestinal tract. New York: Raven, p.975-1009, 1987.

NYACHOTI, C.M.; DE LANGE, C.F.M.; McBRIDE, B.W. et al. Significance of endogenous gut nitrogen losses in the nutrition of growing pigs: a review. Canadian Journal of Animal Science, v.77, p.149-163, 1997.

PÖHLAND, U.; SOUFFRANT, W.C.; SAUER, W.C. et al. Effect of feeding different diets on the exocrine pancreatic secretion of nitrogen, amino acids and enzymes in growing pigs. Journal of Science Food Agriculture, v.62, p.229-237, 1993.

POZZA, P.C. Exigência de treonina digestível para suínos machos castrados e fêmeas dos 15 aos $30 \mathrm{~kg}$. Viçosa, MG: Universidade Federal de Viçosa, 1998,61p. Dissertação(Mestrado em Zootecnia) - Universidade Federal de Viçosa, 1991.

ROSTAGNO, H.S.; SILVA, D.J.; COSTA, P.M.A. et al. Composição de alimentos e exigências nutricionais de aves e suínos (tabelas brasileiras). Viçosa, MG: Universidade Federal de Viçosa, 1983. 61p.

SAUER, W.C.; MOSENTHIN, R.; AHERNS, F. et al. The effect of source of fibre on ileal and fecal amino acid digestibility and bacterial nitrogen excretion in growing pigs. Journal of Animal Science, v.69, p.4070-4077,1991.

SAUER, W.C.; OZIMEK, L. Digestibility of amino acid in swine: results and their practical applications. A review. Livestock Production Science, v.15, p.367-388, 1986.

SERRANO, V.O.S. Digestibilidade dos aminoácidos de suplementos protéicos em suínos, submetidos ou não a anastomose íleo-retal. Viçosa, MG: Universidade Federal de Viçosa, 1989, 55p. Dissertação (Mestrado em Zootecnia) - Universidade Federal de Viçosa, 1989.

SCHULZE, H.; Van LEEUWEN, P.; VERSTEGEN, M.W.A. et al. Effect of level of dietary neutral detergent fiber on ileal apparent digestibility and ileal nitrogen losses in pigs. Journal of Animal Science, v.72, p.2362, 1994.

SCHEEMAN,B.O.Effect of plantfibre onlipase, trypsin and chymotripsin activity. Journal Food Science, v.43, p.634-635, 1978.

SCHEEMAN, B.O.; RICHTER, D.B.; JACOBS, L.R. Response to dietary wheat bran in the exocrine pancreas and intestine of rats. Journal of Nutrition, v.112, p.283-286, 1982.

SHAH, N.; ATTALAH, M.; MAHONEY, R. et al. Effect of dietary fibercomponents on fecal nitrogem excretion and protein utilization in growing rats. Journal of Nutrition, v.112, p.658-666, 1982.

SILVA, D.J. Análise de alimentos: métodos químicos e biológicos. Viçosa, MG: Universidade Federal de Viçosa, 1990. 160p.

UNIVERSIDADE FEDERAL DE VIÇOSA - UFV. Manual de utilização do programa SAEG (Sistema para análises estatísticas e genéticas). Viçosa, MG: Universidade Federal de Viçosa, 1999. 59p.

R. Bras. Zootec., v.32, n.6, p.1354-1361, 2003

Recebido em: 14/05/02

Aceito em: 14/01/03 